NASZA DERMATOLOGIA Online OUR DERMATOLOGY Online

Source of Support: Nil

Competing Interests: None

\section{BEAU'S LINES DUE TO CYTOSTATIC DRUGS IN A PATIENT WITH BREAST CANCER}

\author{
Patricia Chang ${ }^{1}$, Monica Vanesa Vásquez Acajabón² \\ ${ }^{I}$ Department of Dermatology, Hospital General de Enfermedades IGSS and Hospital \\ Ángeles, Guatemala \\ ${ }^{2}$ Hospital General de Enfermedades IGSS and Hospital Ángeles, Guatemala
}

Corresponding author: Patricia Chang, MD PhD

pchang2622@gmail.com
Female patient, 47 years old who was hospitalized due to urinary tract infection, during her hospitalization bullous lesions appeared on her left limb and interconsultation to the Dermatology Department was made.

The patient has been treated by breast cancer with docetaxel, doxorubicin and cyclophosphamide; she had received 5 cycles of chemotherapy

Clinical examination showed vesicles on an erythematous base of the left arm following a linear pattern and the diagnosis of herpes zoster was done. The rest of the clinical examination of the patient showed black color and transverse lines was observed on finger and toenails predominantly on both big toenails seeing four Beau lines on each one (Figs. 1A - J). The diagnosis of Beau's lines and melanonychia of finger and toenails due to cytostatics drugs was done.

The present case shows the normal evolution of the nails after therapy with cytostatics drugs and each transverse line correspond to each cycle of cytostatics drug.

Beau's lines are deep grooved lines in the nail plate $[1,2]$. They result from a sudden interruption of nail keratin synthesis and grow distally with the nail plate. In severe cases if the activity of the matrix is inhibited for 1 to 2 weeks the nail becomes detached (onychomadesis) [3]. It was named after a French physician, Joseph Honoré Simon Beau (1806-1865), described their evolution in typhoid fever and other systemic disorders, in 1846 [4].

It can be caused by chemotherapy (Fig. 2A - E), drug reactions (Fig. 3A - G) (antibiotics like moxifloxacina [5], retinoids, dapsone [3,6] and carbamazepine [6], idiopathic (Fig. 4a - c), trauma and local or systemic diseases [2]. Some of the illness where Beau's Lines had been described include malnutrition, zinc deficiency, pemphigus, Kawasaki disease [2,3], renal failure and infections [4]. Also a nervous habit of repeatedly pushing back the cuticle on one or several finger can cause "washboard nails", due to an obsessive compulsive disorder [3].

The cytotoxic chemotherapeutic agents can induce temporary arrest of proliferative function of the nail matrix, which can be clinically observed as Beau's lines in the nail plate [3,7]. This has been observed in patients who received chemotherapy with placitaxel and docetaxel, this last one being the most frequently responsible for nail matrix damage. Beau's lines are typical signs of acute toxicity to the nail matrix with transient arrest in nail plate production [7].

Beau's lines can vary based upon the width or depth of the depression, reflecting the duration or extent of the damage. The involvement of multiple nails may suggest a systemic cause, including a side effect from medication. Other causes may also be due to metabolic, inflammatory or trauma [3].

As the nail grows (at the rate of $1 \mathrm{~mm} /$ month for toenails and $3 \mathrm{~mm} /$ day for fingernails) [8], the Beau's lines can disappear [1]. And the time course of the illness can be estimated from the position of the Beau's line from proximal nail fold [2]. All Nails can be equally affected, but deformities are frequently noted on thumbnails and toenails due to the slower growth rate [3]. It is important to mention that Beau's lines are normal in neonates, and they have been seen in infants of 8 to 9 weeks. They may disappear around the 14th weeks of life [9]. 


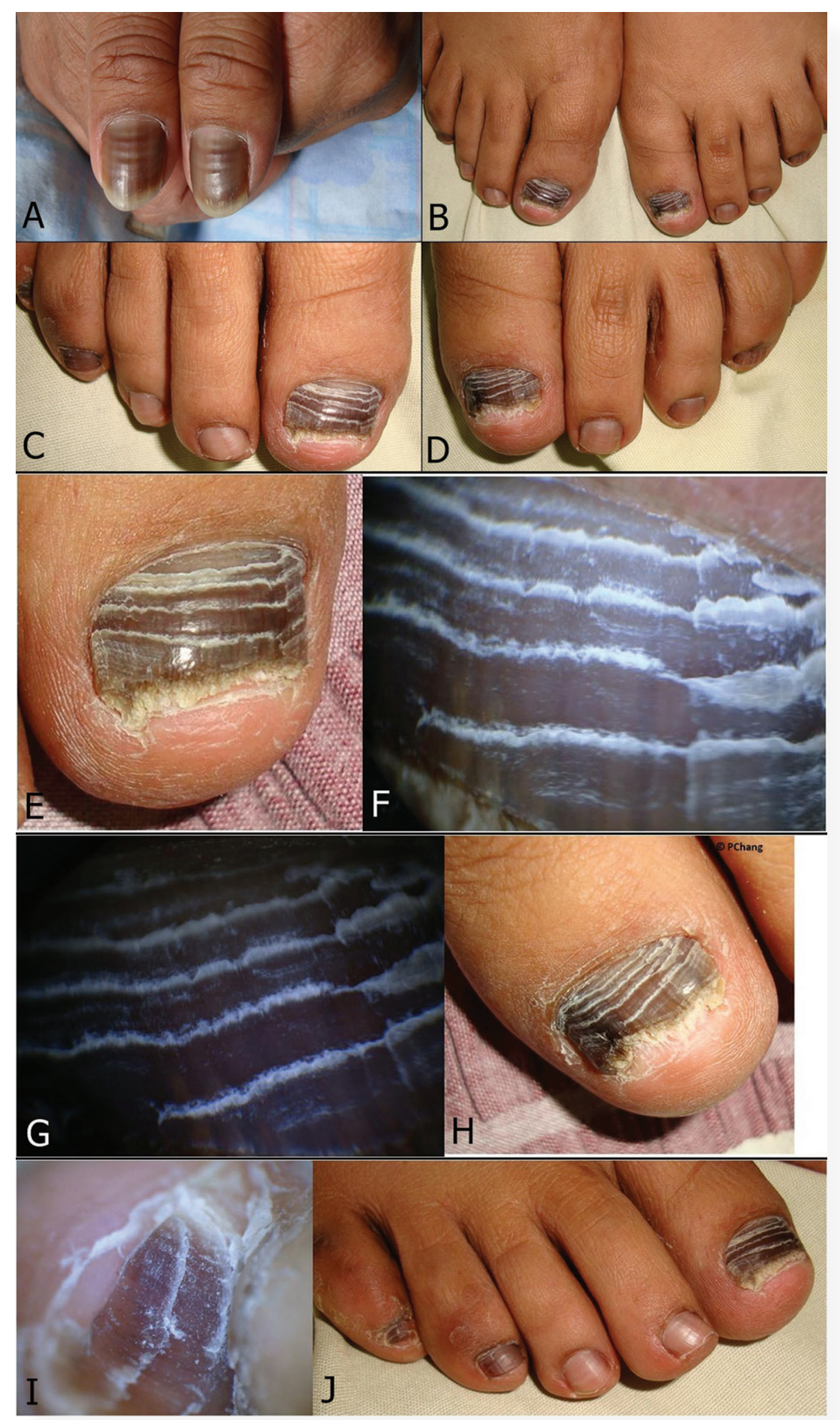

Figure 1A. Beau's lines and melanonychia on fingernails due to docetaxel, doxorubicin and cyclophosphamide in a patient with breast cancer. B. Panoramic view of toenail nail disease. C. Close Up of the Beau's lines on her right foot. D. Close up of the Beau's lines on her left foot. E and F. Dermatoscopic view of the right big toenail with 4 Beau's lines. $\mathbf{G}$ and $\mathbf{H}$. Dermatoscopic view of the left big toenail with 4 Beau's lines. I and J. Dermatoscopic view of the Beau's lines on the fifth toenail. 


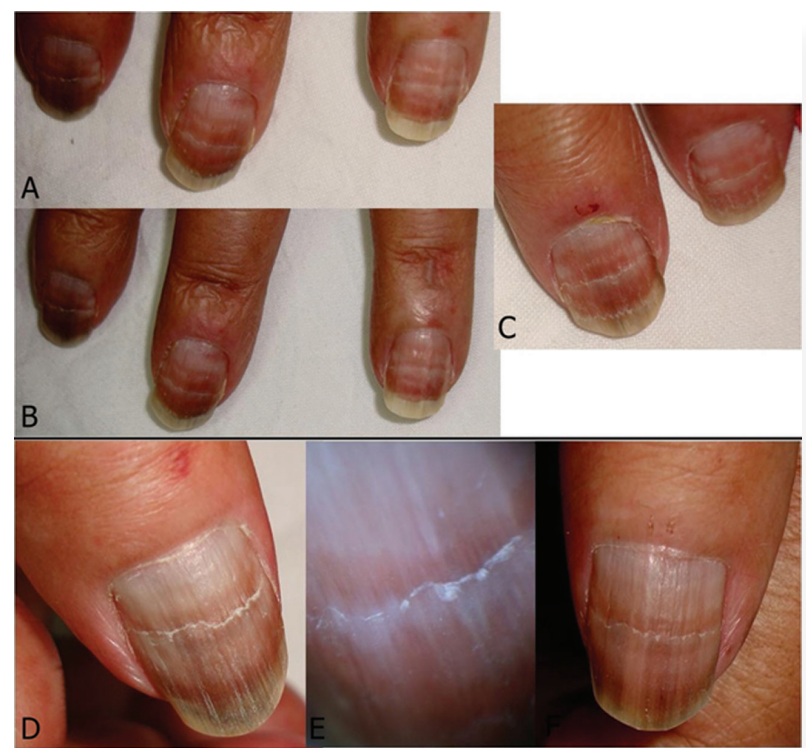

Figure 2A - E. Beau's lines on finger nail in a patient with breast cancer treated with docetaxel.
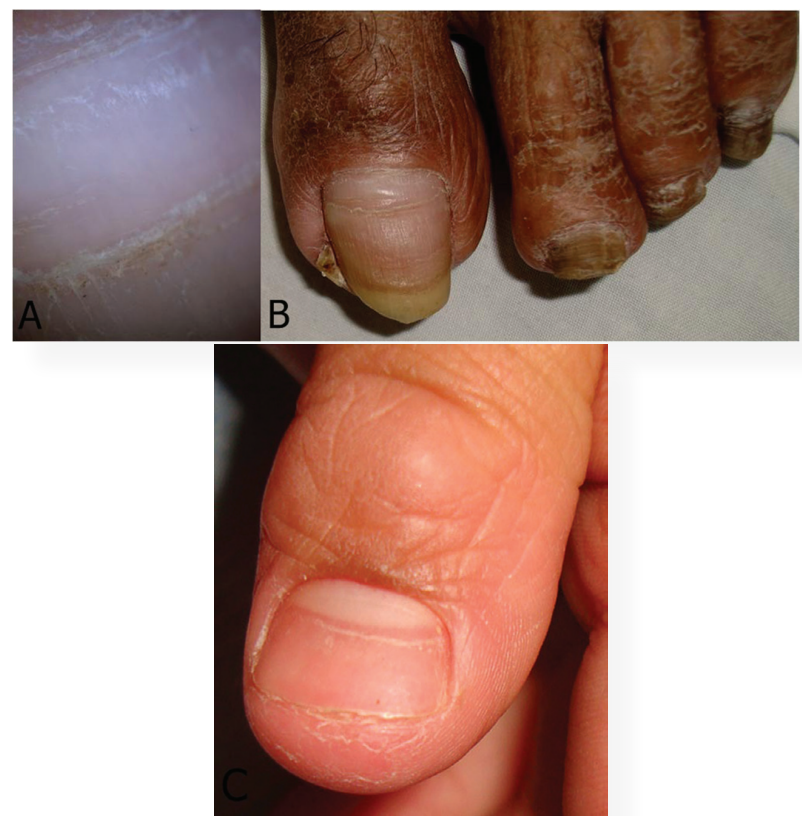

Figure 4A - C. Idiopathic causes of Beau's lines.

\section{REFERENCES}

1. Al Aboud K, Al Aboud A. Names of lines in Dermatology Literature. Our Dermatol Online. 2013;4:251.

2. Sivaram G, Harikrishna J. Beau's lines. Ind J Med Resear. 2013;137:220.

3. Holzberg M. The Nail in Systemic Disease. In Diseases of the nails and their managment Baran R De Berker, D, Holzberg M, \& Thomas L. United Kingdom Willey-BlackWell, 2012: 336-7.

4. Hardin J, Haber RM. Idiopathic Sporadic Onychomadesis. Case Report and Literature Review. JAMA Dermatol. 2012;148:769.

5. Burkhardt O, Allewelt M, Pletz MW, Welte T, Lode H. Beau's Lines in a patient with moxifloxacin for anaerobic pulmonary infection. Scand J Infect Dis. 2003;35:516.
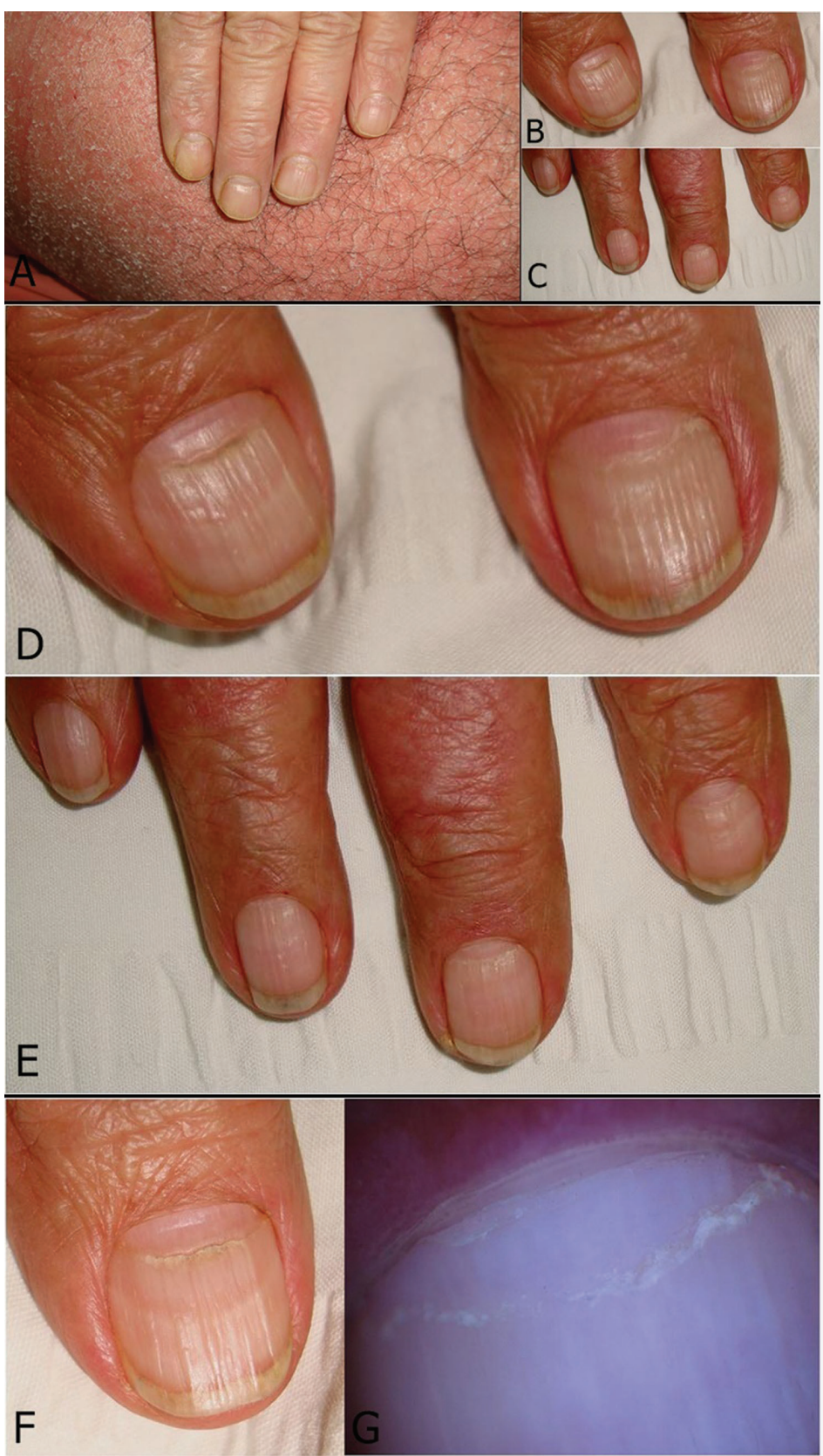

Figure 3A - G. Beau's lines on fingernails in a patient with erythroderma exfoliative due to carbamazepin.
6. Singh G. Nail Changes and Disorders in Elderly. In: Nail \& Its Disorders, Sacchidanand S, Savita AS. New Delhi. Jaypee Brothers Medical Publishers, 2013;79.

7. In SK, Jin WL, Kui YP, Kapsok L, Seong JS, Chang KH. Simultaneous Development of Beau's Lines and Mee's Lines. Ann Dermatol. 2012;24:238-9.

8. Tosti A, Daniel CR, Piraccini BM, Lorizzo M. Abnormal Surface in Color Atlas Nails, Springer, London, 2010:34.

9. Chang P, Rodas C. Las alteraciones de la superficie del plato ungueal en niños. DCMQ. 2013;11:174-81. 